\title{
Solution-phase Synthesis of Zn-doped GaN Photocatalysts: Morphology, Composition, and Catalytic Activity towards Methylene Blue Degradation and 4-nitroaniline Conversion
}

\author{
Keerthi Senevirathne ${ }^{1, *}$, Sanuja Pitigala ${ }^{1}$, Shyamalee Ramaraj ${ }^{1}$, Abdou Lachgar ${ }^{2,3}$, Richard T. Williams ${ }^{2,4}$ \\ ${ }^{1}$ Department of Chemistry, Florida A\&M University, Tallahassee, FL, USA \\ ${ }^{2}$ Center for Energy, Environment, and Sustainability, Wake Forest University, Winston Salem, NC, USA \\ ${ }^{3}$ Department of Chemistry, Wake Forest University, Winston Salem, NC, USA \\ ${ }^{4}$ Department of Physics, Wake Forest University, Winston Salem, NC, USA \\ *Corresponding author: keerthi.senevirathne@famu.edu
}

\begin{abstract}
Solution based synthesis methods; refluxing, base hydrolysis, and hydrothermal synthesis were successfully applied to synthesize shape anisotropic $\mathrm{Zn}$ doped $\mathrm{Ga}_{2} \mathrm{O}_{3}$, followed by subsequent nitridation in ammonia to make corresponding nitride photocatalysts. The catalysts were characterized using different physical characterization methods to evaluate their structure, shape and composition. Photocatalytic methylene blue (MB) degradation and selective hydrogenation of aromatic nitro organic compound 4-nitroaniline (4-NA) were selected to probe reactions under uv-visible and visible light irradiation. $\mathrm{Zn}$ containing nitride catalysts are clearly active on MB degradation and 4-NA conversion under visible light irradiation.
\end{abstract}

Keywords: photocatalysis, Zinc-doped GaN, solution-phase synthesis, shape anisotropy, organic molecule decomposition and conversion

Cite This Article: Keerthi Senevirathne, Sanuja Pitigala, Shyamalee Ramaraj, Abdou Lachgar, and Richard T. Williams, "Solution-phase Synthesis of Zn-doped GaN Photocatalysts: Morphology, Composition, and Catalytic Activity towards Methylene Blue Degradation and 4-nitroaniline Conversion." American Journal of Nanomaterials, vol. 5, no. 2 (2017): 43-50. doi: 10.12691/ajn-5-2-1.

\section{Introduction}

Photocatalysis that utilizes the visible region of the solar spectrum has been a focal point of research on renewable energy and environmental protection. The increase in world energy demand, $\mathrm{CO}_{2}$ emission, and the rapid depletion of fossil fuel resources motivate the search for alternative sources of energy. Conversion of abundant solar energy into chemical energy through photocatalytic water splitting is an interesting and challenging theme that has drawn the interest of physicists and material chemists. [1] Similarly, use of effective photocatalysts that are capable of decomposing organic pollutants utilizing sunlight has drawn much attention too. [2,3] Key requirements of a good photocatalytic material include band gap energy (Eg), stability under irradiation, ease of preparation, and cost effectiveness. The band gap energy is one of the most important parameters because it determines the range of light energy absorption by the catalyst. Band gap engineering is particularly important if the catalyst is expected to be used as a visible light photocatalyst because a significant portion of solar energy $(\sim 43 \%)$ falls within the visible region. [4]
$\mathrm{GaN}$ is a well-known wide band gap semiconductor with a band gap of $3.4 \mathrm{eV}$ at room temperature. [5] It is also reported that $\mathrm{GaN}$ has an excellent chemical stability in both acidic and basic media, which is an added advantage in photocatalysis. However, $\mathrm{GaN}$ is at a disadvantage due to its inability to absorb in the visible region. In order to make $\mathrm{GaN}$ absorb in the visible region, studies have been conducted to modify the band structure through solid solutions of $\mathrm{GaN}$ and metal oxides, especially $\mathrm{ZnO}$. [6,7,8] Metal nitrides and oxynitrides have been developed and studied as photocatalysts owing to their lower band gap energy. Wang and co-workers have studied GaN nanowires synthesized by molecular beam epitaxy and reported its photocatalytic activity towards water splitting. [9] $\mathrm{LaTiO}_{2} \mathrm{~N}$, prepared following the Pechini method using a polymerized complex of La and $\mathrm{Ti}$ metal precursors followed by ammonolysis in a flow of ammonia, has been prepared and tested as an $\mathrm{H}_{2}$ and $\mathrm{O}_{2}$ generating photocatalyst from water in the presence of sacrificial reagents. [10] In addition, a wide range of oxynitrides such as $\mathrm{TaON},[11] \mathrm{Ta}_{3} \mathrm{~N}_{5},[12,13]$ $\mathrm{TaO}_{\mathrm{x}} \mathrm{N}_{\mathrm{y}}$, [14] $\mathrm{TiO}_{2-\mathrm{x}} \mathrm{N}_{\mathrm{x}}$, [15] $\left(\mathrm{Zn}_{1+\mathrm{x}} \mathrm{Ge}\right)\left(\mathrm{N}_{2} \mathrm{O}_{\mathrm{x}}\right)$ [16] have been studied as potential photocatalysts for water splitting, oxidation of methanol, and decomposition of organic pollutants. A variety of synthesis methods have been 
employed in synthesis as well as incorporation of $\mathrm{N}$ into metal oxide lattices. Even though ammonolysis of respective metal oxide material at high temperature under a continuous flow of $\mathrm{NH}_{3}$ gas is the common practice to incorporate $\mathrm{N}$, solution-phase approaches are also reported in the literature. Ho et al. reported a facile solution-phase route to make $\mathrm{TaO}_{\mathrm{x}} \mathrm{N}_{\mathrm{y}}$ visible sensitive photocatalyst. In the study, they applied a sol-gel process using ethylenediamine as the N precursor. [14] Similarly, Burda et al. followed this method in order to achieve $\mathrm{N}$ content as high as $8 \%$ in $\mathrm{TiO}_{2-\mathrm{x}} \mathrm{N}_{\mathrm{x}}$ by direct nitrdation of $\mathrm{TiO}_{2}$ with triethylamine. The palladinated form of the catalyst is reported to be an effective photocatalyst for methylene blue degradation. [17] Domen et al. have reported that metal oxynitrides, in particular, $\left(\mathrm{Zn}_{\mathrm{x}} \mathrm{Ga}_{1-\mathrm{x}}\right)\left(\mathrm{O}_{\mathrm{x}} \mathrm{N}_{1-\mathrm{x}}\right)$ possess appropriate band gap energy and redox potentials for light harvesting. Notably, these oxynitrides are capable of utilizing visible light and act as stoichiometric water splitting photocatalysts when loaded with suitable co-catalysts. [7,18,19,20,21] Based on DFT calculations, the bottom of the conduction band of $\left(\mathrm{Zn}_{\mathrm{x}} \mathrm{Ga}_{1-\mathrm{x}}\right)\left(\mathrm{O}_{\mathrm{x}} \mathrm{N}_{1-\mathrm{x}}\right)$ is mainly formed from $4 \mathrm{~s}$ and $4 p$ orbitals of $\mathrm{Ga}$ while $\mathrm{N} 2 \mathrm{p}$ and $\mathrm{Zn} 3 \mathrm{~d}$ contribute to form the top of the valence band. This orbital arrangement is responsible for $\mathrm{p}-\mathrm{d}$ repulsion, which creates a valence band maximum, resulting in a decrease in Bandgap. [8] Domen's pioneering work of $\left(\mathrm{Zn}_{\mathrm{x}} \mathrm{Ga}_{1-\mathrm{x}}\right)\left(\mathrm{O}_{\mathrm{x}} \mathrm{N}_{1-\mathrm{x}}\right)$ has shed light on a new class of photocatalysts. In his work, solid state reactions between $\mathrm{ZnO}$ and $\mathrm{Ga}_{2} \mathrm{O}_{3}$ at elevated temperatures under a flow of $\mathrm{NH}_{3}$ were employed to synthesize oxynitride photocatalyst. [18] In addition to synthesis of photocatalysts, Domen and others have studied the effect of different compositions and structure of co-catalysts. Among the wide range of co-catalysts studied, core-shell type $\mathrm{Ni} @ \mathrm{NiO}$, [7,22] $\mathrm{Rh} @ \mathrm{Cr}_{2} \mathrm{O}_{3}$ [7] and $\mathrm{RuO}_{2}[19,23]$ have shown significant increase in activity towards overall water splitting. It is reported that the physicochemical state of the core, in core-shell type, and the dispersion plays a significant role in enhancing water splitting. For instance, $\left(\mathrm{Zn}_{\mathrm{x}} \mathrm{Ga}_{1-\mathrm{x}}\right)\left(\mathrm{O}_{\mathrm{x}} \mathrm{N}_{1-\mathrm{x}}\right)$ loaded with $\mathrm{Rh} @ \mathrm{Cr}_{2} \mathrm{O}_{3}$ core-shell co-catalyst has produced 6 and 12 times more $\mathrm{H}_{2}$ than the same core-shell structure in which the core was replaced with $\mathrm{Pt}$ and $\mathrm{Pd}$, respectively. [7]

Environmental pollution remediation is becoming a key issue due to increasing organic pollutants in air and water systems and consequent stringent regulations. Development of new methods to decompose organic pollutants is an imperative task. In this regard, advanced oxidation processes, conducted mainly through in-situ radical generation using solar energy is of great interest. Metal oxide photocatalysts such as $\mathrm{TiO}_{2}$, [24] $\mathrm{Zn}_{2} \mathrm{GeO}_{4}$, [25] and $\mathrm{Cd}_{2} \mathrm{Ge}_{2} \mathrm{O}_{4}$ [26] have been tested for photocatalytic decomposition of organic pollutants in both liquid and gas phase. Similarly, application of semiconductor based photocatalysts in organic conversion is very significant because this method can be applied as a green method in fine chemical production. Among the significant number of organic compounds classified as organic pollutants, nitroanilines have been studied both as a pollutant [27] as well as an important industrial chemical precursor to produce 4-phenylenediamine. [28] $\mathrm{Wu}$ and coworkers reported the use of $\mathrm{In}_{2} \mathrm{Se}_{3}$, under visible light irradiation to transform 4-nitroaniline and discussed the catalyst stability, effect of hole scavengers, and possible photocatalytic hydrogenation mechanism. [28] Liu and coworkers followed an efficient combinatorial method of self-assembly and hydrothermal synthesis to fabricate a CdS-reduced graphene oxide nanocomposite as a photocatalyst for 4-nitroaniline transformation. [3] They attributed enhanced photocatalytic activity observed for this catalyst to enhanced lifetime of photogenerated carriers and better adsorption of nitro organic compound on the composite catalyst. Huang et al. followed a solid state reaction method, similar to Domen's approach, to prepare $\left(\mathrm{Zn}_{1+\mathrm{x}} \mathrm{Ge}\right)\left(\mathrm{N}_{2} \mathrm{O}_{\mathrm{x}}\right)$ using $\mathrm{GeO}_{2}$ and $\mathrm{ZnO}$ precursors at $850^{\circ} \mathrm{C}$ under a flow of ammonia. They demonstrated that the resulting $\left(\mathrm{Zn}_{1+\mathrm{x}} \mathrm{Ge}\right)\left(\mathrm{N}_{2} \mathrm{O}_{\mathrm{x}}\right)$ catalyst is photocatalytically active in the visible range and effectively catalyzes methylene blue, 4-cholorophenol, and salicylic acid. Notably, they observed that the catalyst deactivation, after successive experiments, was quite low and no remarkable changes in the crystal structure and the surface occurred after photocatalytic testing. [16]

In this work, we focus on using $\mathrm{Zn}$-doped $\mathrm{GaN}$, prepared by solution-phase methods, for pollution remediation and organic conversion studies. We report synthetic routes to produce different morphologies of $\mathrm{Zn}$-doped $\mathrm{GaN}$ catalysts characterized as rods, ovals, and spheres. We evaluate their photocatalytic activity towards methylene blue degradation and 4-nitroaniline transformation, as a function of particle morphology and composition. To the authors' best knowledge, a detailed study of Zn-doped $\mathrm{GaN}$ in terms of solution-phase synthesis, morphology, and their photocatalytic activities have not been reported. The prepared catalysts were characterized by various analytical techniques and photcatalytic activity towards methylene blue degradation and 4-nitroaniline conversion. The results are discussed in light of the morphology, surface area, and composition.

\section{Experimental}

\subsection{Synthesis}

\subsubsection{Reflux Synthesis of Rods}

A method employed by Bourret-Courchesne and co-workers [29] was applied, with slight modifications to synthesize $\mathrm{Zn}$-doped $\mathrm{Ga}_{2} \mathrm{O}_{3}$ nanorods. Refluxing precursors in the presence of hexamethylenetetramine at relatively low-temperature causes nucleation and growth of rods. Reaction mixture turned from clear to white when time progresses. In the synthesis, required amounts of $\mathrm{Zn}\left(\mathrm{NO}_{3}\right)_{2}$ and $\mathrm{Ga}\left(\mathrm{NO}_{3}\right)_{3}$ were dissolved in de-ionized water and stirred for 24 hours to ensure formation of a homogeneous mixture. In a separate beaker, $2.0 \mathrm{~g}$ of hexamethylenetetramine was dissolved in $\sim 5 \mathrm{~mL}$ of de-ionized water and added into precursor solution. Next, the solution mixture was refluxed at $100^{\circ} \mathrm{C}$ for 4 hours, cooled down to room temperature, and isolated by centrifugation. Resultant powder was further purified by washing with de-ionized water at least three times and dried at $80^{\circ} \mathrm{C}$ overnight in an oven.

\subsubsection{Room Temperature Synthesis of Ovals}

Similar to the above-mentioned procedure, precursors were dissolved in de-ionized water. After 24 hours of stirring, the required amount of $\mathrm{NH}_{4} \mathrm{OH}$ was added 
dropwise until $\mathrm{pH} \sim 10$. The suspension was stirred for another 6 hours and isolated by centrifugation.

\subsubsection{Hydrothermal Synthesis of Spheres}

Hydrothermal synthesis method was carried to make spheres. Precursors were dissolved in $30 \mathrm{~mL}$ of de-ionized water and stirred for 24 hours. In a separate beaker, $2.4 \mathrm{~g}$ of Pluronic F-127 surfactant was dissolved in $30 \mathrm{~mL}$ of abs. ethanol. Two solutions were mixed and stirred for another $\sim 1$ hour prior to sealing the solution in a Teflon lined autoclave. The reaction was carried out by heating at $200{ }^{\circ} \mathrm{C}$ for 24 hours.

\subsubsection{Calcination and Ammonolysis}

All the samples were calcined at $400^{\circ} \mathrm{C}$ for 6 hours in air prior to nitridation by ammonolysis. Ammonolysis was carried out by heating samples in a flow of ammonia gas. Briefly, calcined samples were placed in alumina crucibles and purged with argon for at least several hours in a tubular furnace. Next, samples were heated at $850^{\circ} \mathrm{C}$ for 8 hours and cooled under a continuous flow of ammonia gas $(100 \mathrm{~mL} / \mathrm{min})$.

\subsubsection{Pt Deposition}

Each catalyst was deposited with $1 \mathrm{wt} \%$ of $\mathrm{Pt}$ as co-catalyst by microwave assisted polyol reduction method. Briefly, $0.25 \mathrm{~g}$ of photocatalyst was mixed with $10 \mathrm{~mL}$ of ethylene glycol and sonicated for 1-2 hours in a sonicator bath in order to uniformly disperse the catalyst. Next, $0.007 \mathrm{~g}$ of $\mathrm{Pt}$ precursor $\left(\mathrm{H}_{2} \mathrm{PtCl}_{6} \cdot 6 \mathrm{H}_{2} \mathrm{O}\right)$ was dissolved in $\sim 2 \mathrm{~mL}$ of ethylene glycol and mixed with photocatalyst dispersion by stirring overnight. Reduction of Pt precursor was carried out under microwave irradiation for 3 minutes at $180^{\circ} \mathrm{C}$. Sample was recovered by centrifugation and series of washing with de-ionized water to remove ethylene glycol and dried in an oven at $70^{\circ} \mathrm{C}$ overnight.

\subsection{Physical Characterization}

\subsubsection{Powder X-ray Diffraction (PXRD)}

The X-ray patterns were identified by matching with available phases in the EVA diffraction database. A Bruker-AXS D2 Phaser Powder diffractometer (XRD) equipped with a Ni-filtered $\mathrm{Cu} \mathrm{K} \mathrm{K}_{\alpha}$ sealed X-ray tube $(\lambda=1.54184 \AA)$ and a Lynxeye position-sensitive detector was used for X-ray analysis. The diffractometer was operated at $30 \mathrm{kV}$ and $10 \mathrm{~mA}$ with a step width of $0.015^{\circ}$ and a scan rate of $1.5^{\circ} / \mathrm{min}$. The X-ray powder diffraction pattern was measured at room temperature and analyzed using the Bruker-AXS EVA software package.

\subsubsection{Scanning Electron Microscopy (SEM)}

A JEOL 6330 cold field emission scanning electron microscope, operated at $10 \mathrm{kV}$ was used to collect SEM images. A small amount of sample was spread on a carbon tape adhered to an aluminum specimen holder. The Quartz PCI software was used to collect and record images.

\subsubsection{Surface area and Porosity Analysis}

A Quantachrome ASiQC 0100-2 Surface Area Analyzer was used in surface area and porosity analysis. Powder samples were out-gassed at $120^{\circ} \mathrm{C}$ for 2 hours prior to analysis. The specific surface area of samples was evaluated by $\mathrm{N}_{2}$ adsorption-desorption and by applying the Brunauer, Emmet, and Teller (BET) method.

\subsubsection{Photocatalytic Experiments}

Photocatalytic activities of the catalysts were evaluated via degradation and conversion of $\mathrm{MB}$ dye and 4-NA, respectively. Photocatalytic measurements were carried out in a $85 \mathrm{~mL}$ quartz photolysis cell. Briefly, $0.1 \mathrm{~g}$ of catalyst was suspended in $30 \mathrm{~mL}$ of aqueous 20 ppm MB or 4-NA solution in a quartz photolysis cell. The suspension was stirred in the dark for 30 minutes to achieve equilibrium of MB adsorbed on the catalyst. After 30 minutes, the suspension was irradiated with a $200 \mathrm{~W}$ super-pressure mercury lamp with or without applying uv cut off optical filters to initiate the decomposition reaction. At chosen irradiation time intervals, a small aliquot was drawn into a syringe, centrifuged to remove the catalyst, and analyzed with a Agilent 8453 uv-visible spectrophotometer using a cell with $1 \mathrm{~cm}$ pathlength. In spectrophotometric measurements, the degradation of $\mathrm{MB}$ was monitored by measuring the absorbance at $\lambda_{\max } 665 \mathrm{~nm}$. In 4-NA conversion, absorbance was measured at $\lambda_{\max } 238$ and 380 $\mathrm{nm}$, which correspond with product and precursor peaks, respectively.

\section{Results and Discussion}

\subsection{X-ray Diffraction Measurements}

$\mathrm{X}$-ray diffraction analysis was carried out to evaluate the structure, crystallinity, and crystallite sizes of photocatalysts. Figure 1(a) shows X-ray patterns of 2-6\% $\mathrm{Zn}$-doped $\mathrm{Ga}_{2} \mathrm{O}_{3}$ calcined at $400^{\circ} \mathrm{C}$ for 6 hours in air. Figure 1(b) shows the X-ray patterns for $\mathrm{Zn}$-doped $\mathrm{GaN}$ photocatalysts ammonolysed at $850^{\circ} \mathrm{C}$ for 8 hours in a flow of ammonia. It is evident from comparison of (a) and (b) that the $\mathrm{Zn}$-doped $\mathrm{Ga}_{2} \mathrm{O}_{3}$ calcined at $400^{\circ} \mathrm{C}$ is less crystalline than corresponding patterns of nitrides and shows a broad background indicating the presence of some amorphous components. However, the observed crystalline pattern shown in Figure 1(a) matches well with the calculated pattern of $\beta-\mathrm{Ga}_{2} \mathrm{O}_{3}$ in terms of peak positions and intensity. Further increase in the calcinations temperature of $\mathrm{Zn}$-doped $\mathrm{Ga}_{2} \mathrm{O}_{3}$ to $850^{\circ} \mathrm{C}$ results sharp $\mathrm{XRD}$ reflections (Figure 1(a) insert) indicating higher crystallinity. Nitridation of $\mathrm{Zn}$-doped $\mathrm{Ga}_{2} \mathrm{O}_{3}$ at $850^{\circ} \mathrm{C}$ for 8 hours in a flow of ammonia resulted in a single hexagonal wurtzite phase, which is similar to GaN. However, the $2 \theta$ reflections at $\sim 57.5$ and $63^{\circ}$ slightly shifted to lower angles in $\mathrm{Zn}$-doped $\mathrm{GaN}$ in comparison to $\mathrm{GaN}$ indicating $\mathrm{Zn}$ incorporation into $\mathrm{Ga}_{2} \mathrm{O}_{3}$ lattice. There were no extra peaks due to $\mathrm{ZnO}, \mathrm{ZnGa}_{2} \mathrm{O}_{3}$, or $\mathrm{Ga}_{2} \mathrm{O}_{3}$ indicating that the material is phase pure.

\subsection{Morphological Characterization of $\mathrm{Zn}$-doped $\mathrm{Ga}_{2} \mathrm{O}_{3}$ and $\mathrm{Zn}$-doped $\mathrm{GaN}$}

$\mathrm{Zn}$-doped $\mathrm{Ga}_{2} \mathrm{O}_{3}$ as well as respective $\mathrm{GaN}$ show rod, oval, and spherical morphology as a function of the synthesis method. Scanning electron microscopy was employed to evaluate the morphology of photocatalysts 
obtained before and after nitridation (Figure 2). Samples prepared by reflux method at $100^{\circ} \mathrm{C}$ in the presence of hexamethylenetetraamine have rod shapes with sizes in the micron range. The higher magnification image of rods, before nitridation (Figure 2(a) inset), evidences a smooth surface, which apparently has been changed upon nitridation and becomes more porous. However, this behavior is not in correspondence with BET surface area data. The BET surface area decreases upon nitridation in all the samples analyzed. We assume that this decrease is observed due to high temperature applied during ammonolysis, which causes material sintering. The average length and diameter of rods are approximately $3 \mu \mathrm{m}$ and $0.2 \mu \mathrm{m}$, respectively. The synthesis temperature is important in this method of synthesis because temperatures lower than $70^{\circ} \mathrm{C}$ produce some irregular shaped particles, not rods. Oval shaped particles were prepared at room temperature using aq. ammonia as the precipitating agent. Synthesis of spheres was achieved following a hydrothermal synthesis in combination with surfactant Pluronic F-127. The spheres are clearly polydisperse with a size is in micron range and retain the morphology upon nitridation.

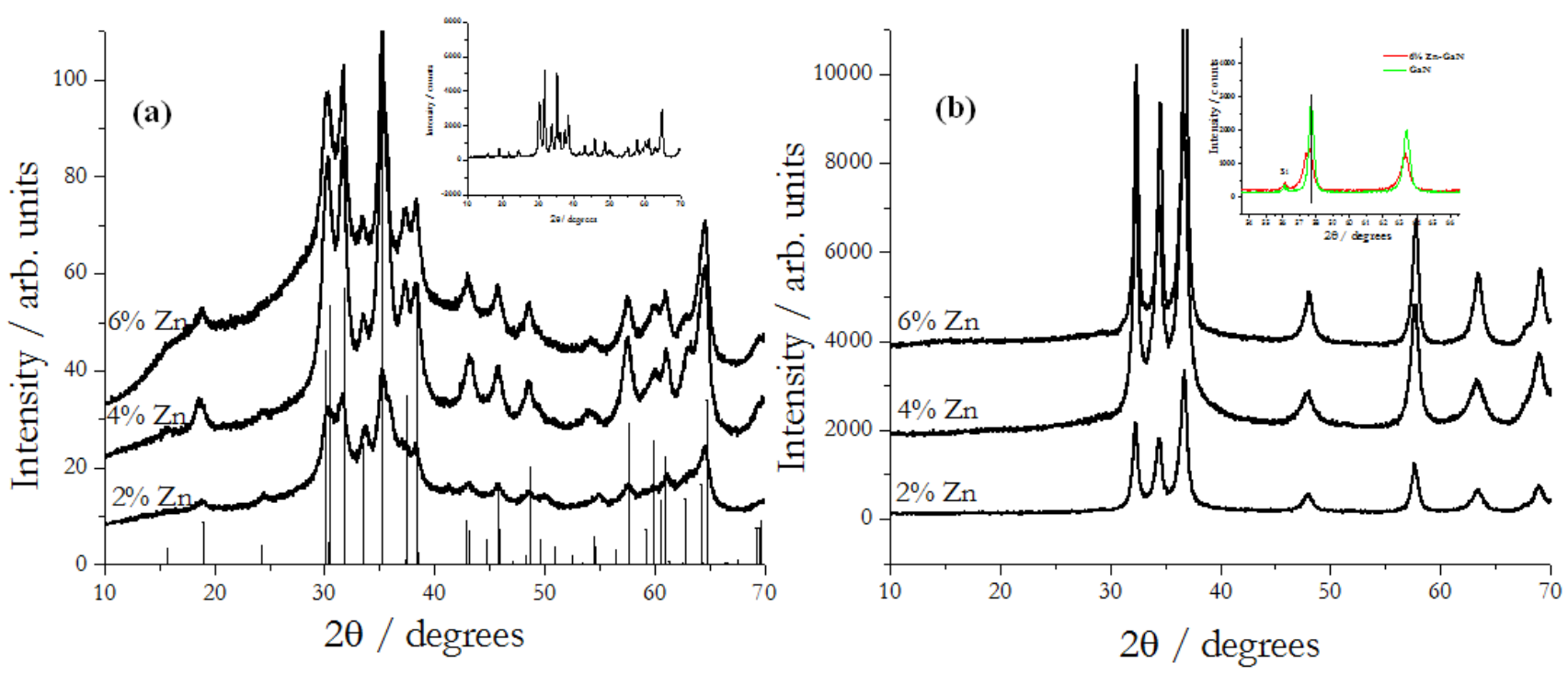

Figure 1. XRD spectra of (a) $\mathrm{Zn}$-doped $\mathrm{Ga}_{2} \mathrm{O}_{3}$ and their respective (b) oxynitride counterparts, as a function of percent $\mathrm{Zn}$ content. Vertical solid line pattern of Fig.1a is the calculated XRD reflections of $\beta-\mathrm{Ga}_{2} \mathrm{O}_{3}$ phase. Inserts to Figure 1 (a) and (b) show XRD patterns of $\mathrm{Zn}$-doped Ga $\mathrm{O}_{3}$ calcined at $850^{\circ} \mathrm{C}$ in air and $\mathrm{XRD}$ of $\mathrm{GaN}$ and $\mathrm{Zn}-\mathrm{GaN}$, respectively
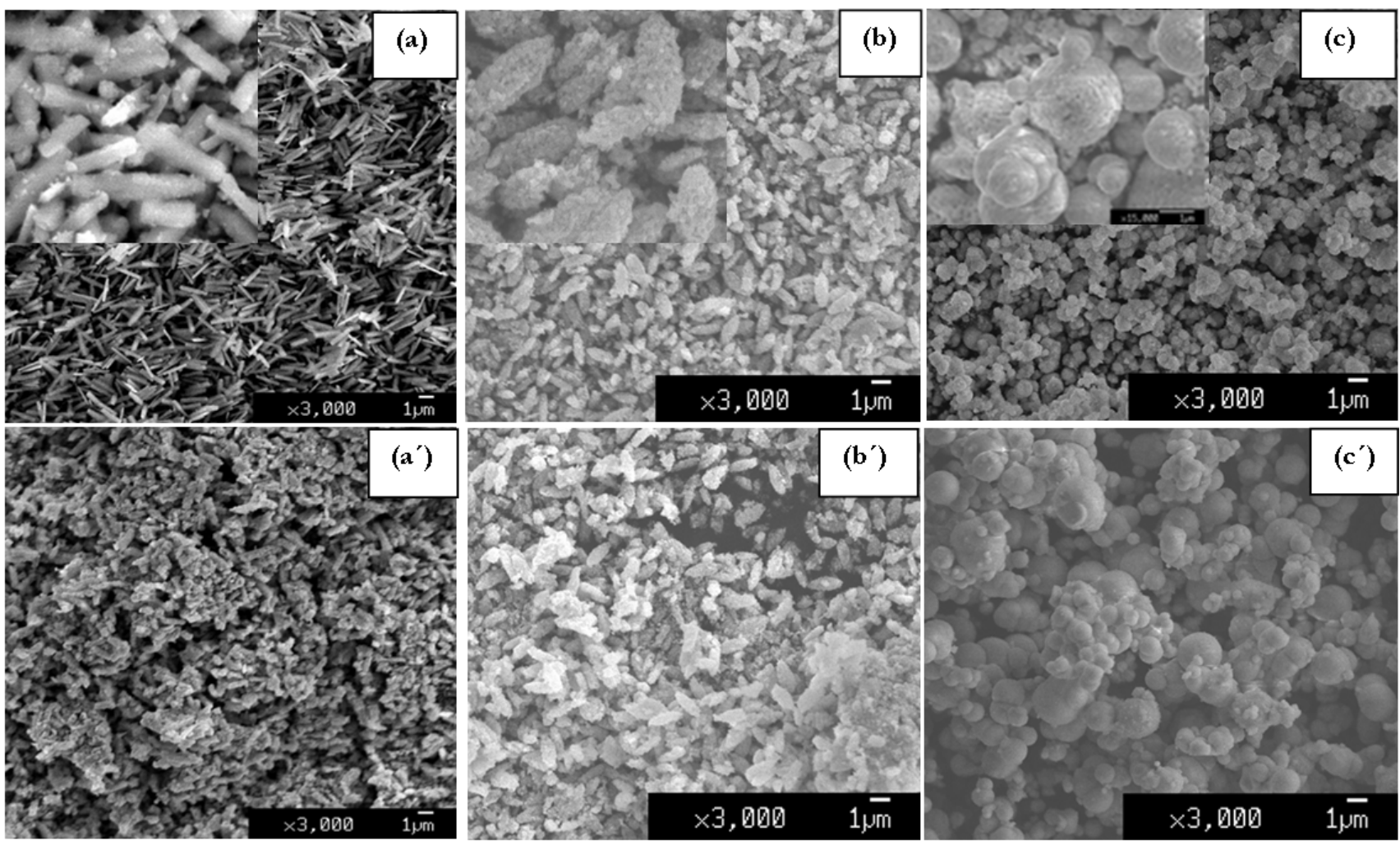

Figure 2. Scanning electron microscopic images of $\mathrm{Zn}$-doped $\mathrm{Ga}_{2} \mathrm{O}_{3}$ rods (a), ovals (b), and spheres (c) and their corresponding $\mathrm{Zn}$-doped GaN counterparts. The insets in the upper panel show corresponding high magnification images 


\subsection{Surface Area Measurements of $\mathrm{Zn}$-doped $\mathrm{Ga}_{2} \mathrm{O}_{3}$ and $\mathrm{Zn}$-doped $\mathrm{GaN}$}

In order to probe the surface area of photocatalysts, nitrogen adsorption-desorption isotherms were acquired. Representative adsorption-desorption isotherms have been given in Figure 3 along with BET surface area data in Table 1. Surface areas were determined by application of the Brunauer-Emmet-Teller model. The adsorptiondesorption isotherm for $\mathrm{Zn}$-doped $\mathrm{Ga}_{2} \mathrm{O}_{3}$ shows a type IV curve, characteristic of mesoporous $(2-50 \mathrm{~nm}$ pore diameter) material, with a sharp upturn in the high relative pressure region due to liquid condensation in macropores $(>50 \mathrm{~nm})$. Upon nitridation, the adsorption-desorption isotherm changes and the hysteresis is not as significant. Additionally, the adsorption volume of $\mathrm{Zn}$-doped GaN material decreases relative to $\mathrm{Zn}$-doped $\mathrm{Ga}_{2} \mathrm{O}_{3}$ in a given relative pressure. This observation is in agreement with corresponding surface area values observed for particular samples. For each particle shape, the surface area of $\mathrm{Zn}$-doped $\mathrm{Ga}_{2} \mathrm{O}_{3}$ is higher than the respective nitride (Table 1). This is probably because of high temperature nitridation, which may cause pore collapse and/or particle sintering.

Table 1. BET surface areas of oxide and nitride photocatalysts with different morphologies

\begin{tabular}{|l|l|}
\hline Sample & Surface area $/ \mathrm{m}^{2} \mathrm{~g}^{-1}$ \\
\hline $4 \% \mathrm{Zn}-\mathrm{Ga}_{2} \mathrm{O}_{3}$ (rods) & 75 \\
$4 \% \mathrm{ZnGaON}$ (rods) & 6.0 \\
$4 \% \mathrm{Zn}-\mathrm{Ga}_{2} \mathrm{O}_{3}$ (ovals) & 93 \\
$4 \% \mathrm{ZnGaON}$ (ovals) & 11 \\
$4 \% \mathrm{Zn}-\mathrm{Ga}_{2} \mathrm{O}_{3}$ (spheres) & 245 \\
$4 \% \mathrm{ZnGaON}$ (spheres) & 26 \\
\hline
\end{tabular}

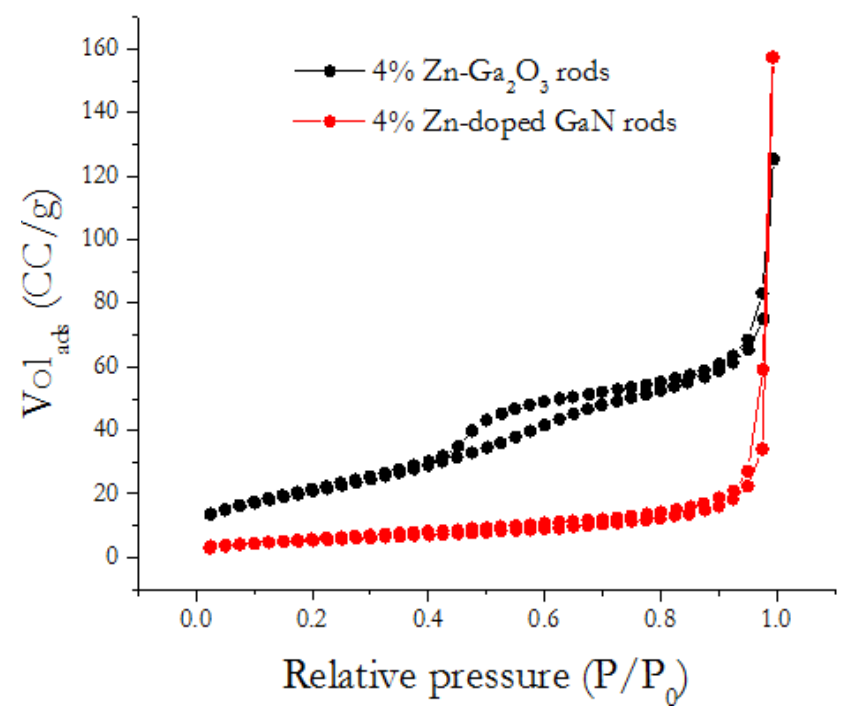

Figure 3. A representative $\mathrm{N}_{2}$ adsorption-desorption isotherms of $4 \%$ $\mathrm{Zn}$-doped $\mathrm{Ga}_{2} \mathrm{O}_{3}$ and $\mathrm{Zn}$-doped $\mathrm{GaN}$

\subsection{Diffuse Reflectance Uv-visible Absorption Measurements}

In order to estimate the band gap energy of $\mathrm{Zn}$-doped GaN, uv-visible diffuse reflectance spectra (DRS) were acquired on photocatalysts with different $\mathrm{Zn}$ contents. Band gaps were determined by applying Kubelka-Munk theory to the diffuse reflectance data. [30] Figure 4 shows representative DRS spectra of $\mathrm{Zn}$-doped $\mathrm{GaN}$ photo-catalysts containing varying amounts of $\mathrm{Zn}$. Samples possess two prominent interband absorptions; one in the visible region and the other in the uv region. This observation may suggest that the samples are not direct band gap semiconductors with intrinsic absorption edges. The $\mathrm{Zn}$ dopant is likely to act as an impurity band. It can be seen that all samples have an lower absorption edge at approximately $2.7 \mathrm{eV}$, which is close to the band gap reported for $\mathrm{Zn}_{\mathrm{x}} \mathrm{Ga}_{1-\mathrm{x}} \mathrm{O}_{\mathrm{x}} \mathrm{N}_{1-\mathrm{x}}($ where $\mathrm{x}=0.05-0.11)$. [18]

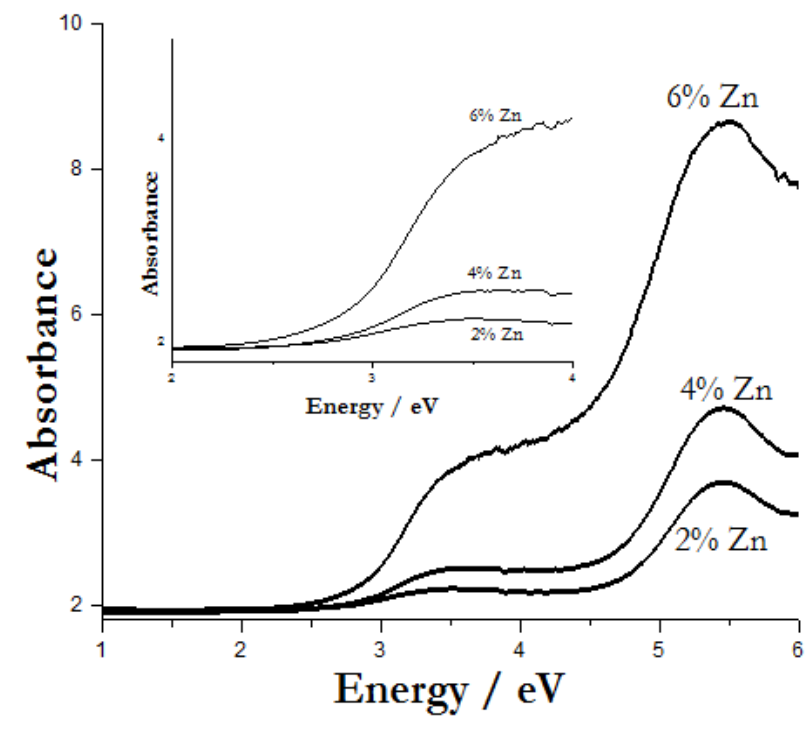

Figure 4. Relative absorption calculated via a Kubelka-Munk method using uv-visible diffuse reflectance data $\mathrm{Zn}$-doped $\mathrm{GaN}$ photocatalysts. The inset provides an expanded view of the spectra in the energy range of 2 to $4 \mathrm{eV}$

\subsection{Photocatalytic Decomposition of MB and Conversion of 4-NA}

The photocatalytic decomposition of $\mathrm{MB}$ and 4-NA conversion was used as model reactions to evaluate the activity of $\mathrm{Zn}$-doped $\mathrm{GaN}$ photocatalysts. It is known that $\mathrm{MB}$ strongly absorbs in the visible region giving rise to two distinct absorption peaks at 612 and $665 \mathrm{~nm}$.[31] As a control experiment, reactions were first carried out in the absence of a catalyst, under similar experimental conditions that were applied in the presence of a catalyst. Absorbance profiles of MB and 4-NA in the absence of catalyst were collected under uv-visible irradiation (Figure 5a \&c). Representative uv-visible absorption profiles of $\mathrm{MB}$ and 4-NA decomposition in the presence of oval-shaped $4 \%$ $\mathrm{Zn}$-doped $\mathrm{GaN}$ photocatalyst is shown in Figure $5 \mathrm{~b} \& \mathrm{~d}$, respectively. As shown in Figure $5 \mathrm{a} \& \mathrm{c}$, relative absorbance change of $\mathrm{MB}$ and 4-NA in the absence of a catalyst is negligible, which indicates that the light irradiation itself has no effect in $\mathrm{MB}$ decomposition or 4-NA conversion. However, it can be seen that uv-visible and visible light irradiation of $\mathrm{MB}$ in the presence of $\mathrm{Zn}$ doped GaN catalysts exhibited a decrease in $\mathrm{MB}$ concentration as the time of irradiation progressed. It is noteworthy that the concentration decrease in the first hour upon irradiation is quite significant, but as time 
progresses; the effect levels off. For 4-NA conversion activity calculations, the decrease in the absorbance peak at $380 \mathrm{~nm}$ was used. A decrease in the absorption of 4-NA at $380 \mathrm{~nm}$ along with simultaneous appearance of a peak at $238 \mathrm{~nm}$ was observed. Based on the literature reports, another small peak at $305 \mathrm{~nm}$ should be visible. [28] However, in our work that peak is not quite visible, possibly due to low resolution of the uv-visible spectra. Upon irradiation, 4-NA undergoes selective reduction to form 4-phenyldiamine (4-PDA), which is the product that characteristically absorb at $238 \mathrm{~nm}$. Similar to $\mathrm{MB}$ decomposition, the control experiment (4-NA without a catalyst) exhibits negligible photocatalytic hydrogenation of 4-NA (Figure 5c) indicating photo hydrogenation can be ignored in the absence of a catalyst.

The plot of $\mathrm{C} / \mathrm{C}_{0}$ as a function of irradiation time is shown in Figure 6. $\mathrm{C}$ is the concentration of $\mathrm{MB}$ or 4-NA in the reaction mixture and $\mathrm{C}_{0}$ is the initial concentration. The relative concentration change of $\mathrm{MB}$ in the absence of a catalyst is approximately $13 \%$. The concentration change of $\mathrm{MB}$ in the presence of a catalyst ranges from 74 to $87 \%$ after 5 hours of uv-visible irradiation (Figure 6a). Among the catalysts tested the $\mathrm{Zn}$-doped GaN containing $4 \% \mathrm{Zn}$ shows the highest $\mathrm{MB}$ decomposition ( $\sim 87 \%)$ under uv-visible irradiation. However, it is not possible to conveniently draw a comparison between 2 and $6 \%$ doped samples. Therefore, 4\% Zn-doped GaN was used to check the photocatalytic decomposition of $\mathrm{MB}$ under visible light irradiation and conversion of 4-NA under uv-visible light irradiation. The photocatalytic activity in terms of $\mathrm{MB}$ decomposition, changes in the order spheres $>$ ovals $>$ rods. This activity trend correlates with the catalyst surface area. Spheres, irrespective of oxide or nitrides, possess the highest surface area while rods have the lowest. Higher catalytic activity of spheres can be attributed to higher surface area, which in turn provides enhanced accessibility of photogenerated carriers towards $\mathrm{MB}$ and 4-NA. The MB decomposition under visible light irradiation is lower (46-52\%) (Figure 6b) than the decomposition under uv-visible light irradiation. This is due to the fact that irradiance of the super pressure mercury lamp is strongest in the ultraviolet region.

Photocatalytic conversion of 4-NA into 4-PDA was tested under uv-visible irradiation using 4\% Zn-doped $\mathrm{GaN}$ catalyst. The maximum conversion under uv-visible irradiation was calculated based on the absorbance at 380 nm. Absorbance of the reactant peak at $380 \mathrm{~nm}$ in the presence and absence of a catalyst is 9 and $\sim 60 \%$ after 5 hours, respectively. The percentage conversion increases upon further irradiation (e.g. $\sim 80 \%$ after 7 hours, data not shown). Similar to MB decomposition, 4\% Zn-doped GaN spheres shows the highest conversion even though the activity difference among different morphologies is not that significant.
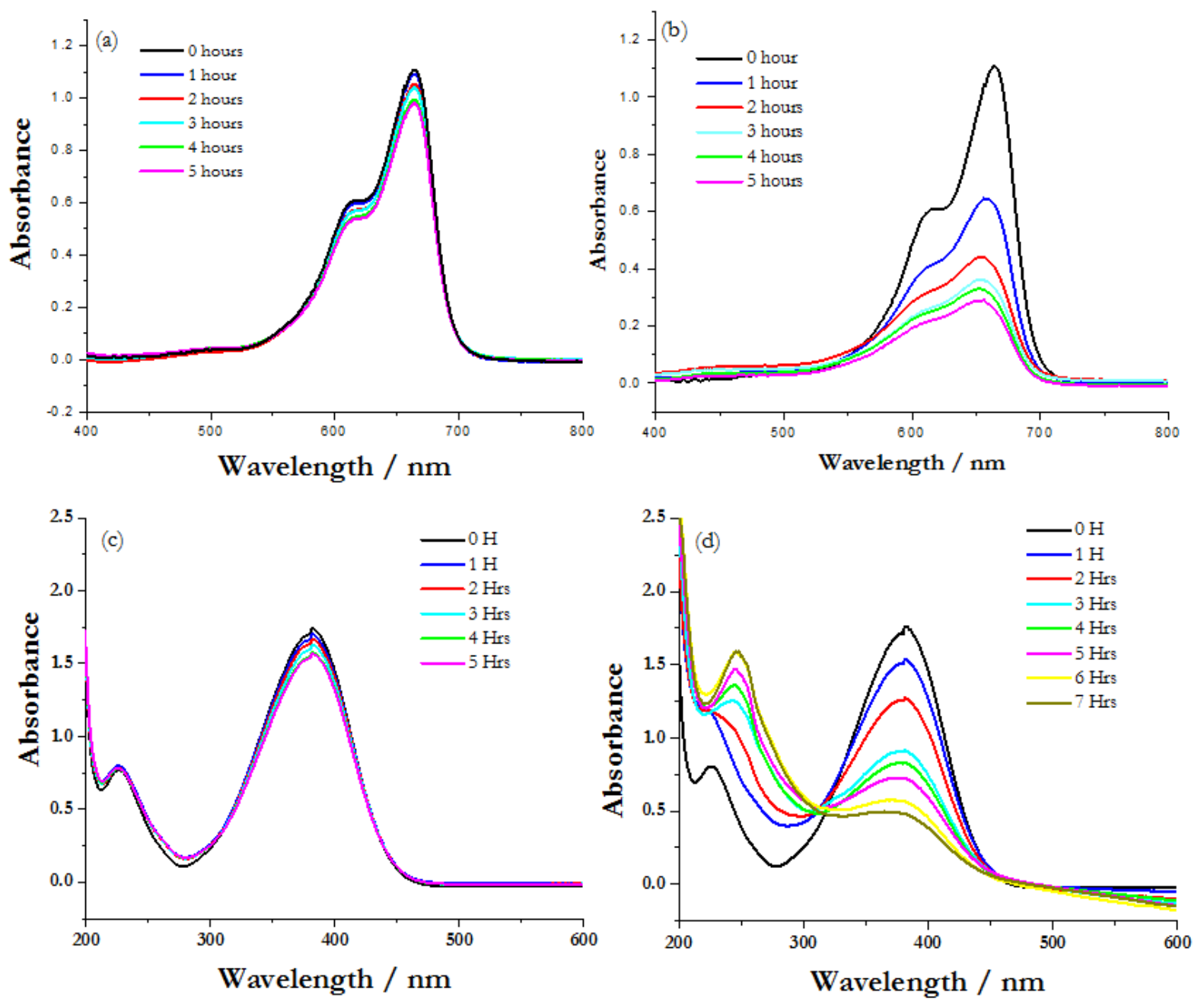

Figure 5. Representative absorbance spectra for specified time of uv-visible illumination of methylene blue (MB) and $p$-nitroaniline ( $p$-NA) solutions in the absence $(a, c)$ or presence $(b, d)$ of $4 \% \mathrm{Zn}$-doped GaN photocatalysts 

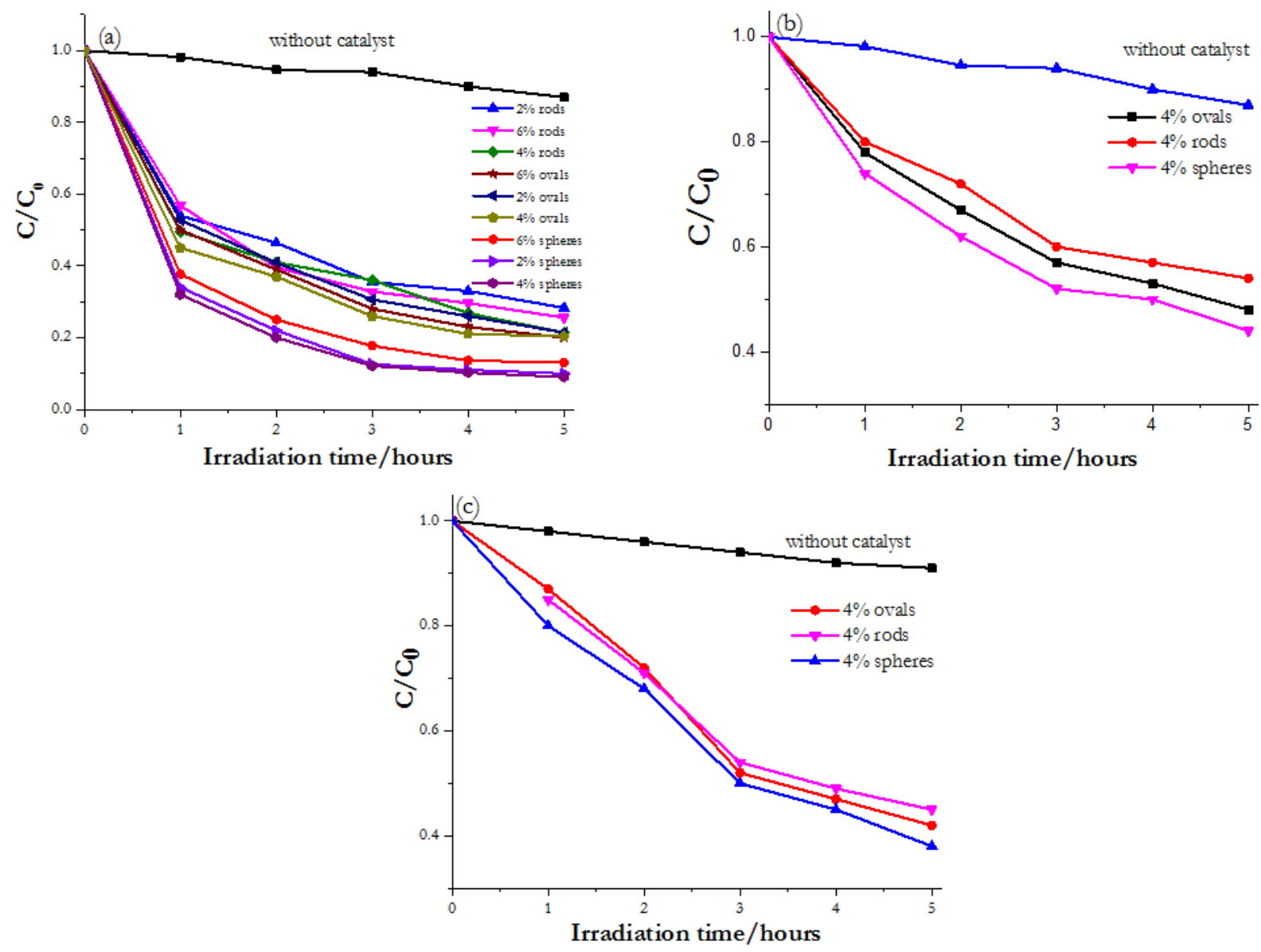

Figure 6. Relative concentration vs. time plots of $\mathrm{MB}$ decomposition in the presence of various photocatalysts under (a) uv-visible (b) visible light irradiation. Figure 6 (c) shows relative concentration changes of 4-NA under uv-visible irradiation

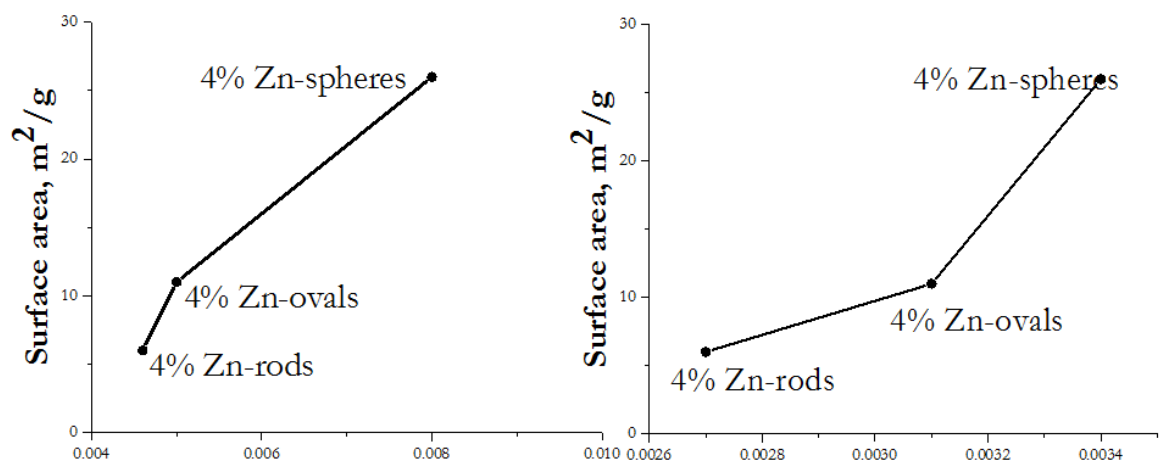

Pseudo first order rate constant, $\min ^{-1}$ Pseudo first order rate constant, $\min ^{-1}$

Figure 7. Rate constant as a function of surface area and shape

The kinetic analysis of photocatalytic degradation of $\mathrm{MB}$ and 4-NA reveals that the degradation process follows a pseudo first order kinetics, which can be explained by the following equation (Eqn-1).

$$
\operatorname{Ln}\left(\mathrm{C}_{\mathrm{o}} / \mathrm{C}\right)=\mathrm{kt}
$$

Where $\mathrm{Co}, \mathrm{C}$, and $\mathrm{k}$ are initial concentration of organic pollutants, concentration at time t, and rate constant, respectively. The respective rate constants were calculated and plotted against the surface area (Figure 7), in turn the shape of catalysts materials. The rate constant of MB degradation with $4 \% \mathrm{Zn}$-doped $\mathrm{GaN}$ spheres is 1.6 and 1.8 times higher than those of $4 \% \mathrm{Zn}$-doped GaN ovals and rods, respectively. Higher catalytic activity of spheres may be attributed to higher surface area, which provides more catalytic sites and enhanced accessibility to photogenerated carriers. Under similar conditions, the rate constants of 4-NA degradation with $4 \%$ Zn-doped GaN spheres, ovals, and rods were calculated to be almost the same (Figure 7).

\section{Conclusions}

Rod, oval, and spherical Zn-doped GaN photocatalysts were synthesized by applying a solution-phase method and were characterized by XRD, electron microscopy, surface area analysis, and spectroscopy. Catalysts were evaluated for $\mathrm{MB}$ decomposition and 4-NA conversion into 4-PDA under visible and uv-visible light irradiation 
in the absence of a hole scavenger. All catalysts showed activity towards $\mathrm{MB}$ degradation and 4-NA while 4\% $\mathrm{Zn}$-doped $\mathrm{GaN}$ being the highest active catalysts. Based on absorbance data and kinetic analysis, it is clear that the surface area and catalytic activity is correlated. We have seen that higher surface area catalysts (spheres) are more active than those of lower surface area catalysts.

\section{Acknowledgements}

This work has been financially supported by the Center for Energy, Environment, and Sustainability of the Wake Forest University and by the Four Universities Solar Consortium under a Triad Interuniversity Project of Wake Forest University, North Carolina A\&T, University of North Carolina Greensboro, and Winston Salem State University. Authors gratefully acknowledge Drs. Arachchige and Ranamohotti, Virginia Commonwealth University for granting access to use uv-vis spectrophotometer for diffuse reflectance analysis.

\section{References}

[1] Maeda, K. and Domen, K. "New non-oxide photocatalysts designed for overall water splitting under visible light". J. Phys. Chem. C 111. 7851-7861. 2007.

[2] Wu, W., Liu, G., Liang, S., Chen, Y., Shen, L., Zheng, H., Yuan, R., Hou, Y. and Wu, L. "Efficient visible-light-induced photocatalytic reduction of 4-nitroaniline to p-phenylenediamine over nanocrystalline $\mathrm{PbBi}_{2} \mathrm{Nb}_{2} \mathrm{O}_{9}$ ". J. Catal. 290. 13-17. 2012.

[3] Liu, S., Chen, Z., Zhang, N., Tang, Z.-R. and Xu, Y.-J. "An efficient self-assembly of CdS nanowires-reduced graphene oxide nanocomposites for selective reduction of nitro organics under visible light irradiation". J. Phys. Chem. C 117. 8251-8261. 2013.

[4] Ni, M., Leung, M.K.H., Leung, D.Y.C. and Sumathy, K. "A review and recent developments in photocatallytic water splitting using $\mathrm{TiO}_{2}$ for hydrogen production". Renew. Sustain. Energy Rev. 47. 401-425. 2007.

[5] Jung, H.S., Hong, Y.J., Li, Y., Cho, J., Kim, Y.-J. and Yi, G.-C. "Photocatalysis using GaN nanowires". ACS Nano 2. 637-642. 2008.

[6] Wu, A., Li, J., Liu, B., Yang, W., Jiang, Y., Liu, L., Zhang, X., Xiong, C. and Jiang, X. "Band-gap tailoring and visible-light driven photocatalytic performance of porous $(\mathrm{GaN})_{1-\mathrm{x}}(\mathrm{ZnO})_{\mathrm{x}}$ solid solution". Dalton Trans. 46. 2643-2652. 2017.

[7] Maeda, K., Sakamoto, N., Ikeda, T., Ohtsuka, H., Xiong, A., Lu, D., Kanehara, M., Teranishi, T. and Domen, K. "Preparation of core-shell-structured nanoparticles (with a noble-metal or metal oxide core and a chromia shell) and their application in water splitting by means of visible light." Chem. Eur. J. 16. 7750-7759. 2010.

[8] Maeda, K., Takata, T., Hara, M., Saito, N., Inoue, Y., Kobayashi, H. and Domen, K. "GaN:ZnO solid solution as a photocatalyst for visible-light-driven overall water splitting." J. Am. Chem. Soc. 127. 8286-8287. 2005.

[9] Wang, D., Pierre, A., Kibria, M.G., Cui, K., Han, X., Bevan, K.H., Guo, H., Paradis, S., Hakima, A.-R. and Mi, Z. "Wafer level photocatalytic water splitting on $\mathrm{GaN}$ nanowire arrays grown by molecular beam epitaxy". Nano Lett. 11. 2353-2357. 2011.

[10] Kasahara, A., Nukumizu, K., Hitoki, G., Takata, T., Kondo, J., Hara, M., Kobayashi, H. and Domen, K. "Photoreactions on $\mathrm{LaTiO}_{2} \mathrm{~N}$ under visible light irradiation". J. Phys. Chem. A 106. 6750-6753. 2002.

[11] Ito, S., Thampi, K.R., Comte, P., Liska, P. and Gratzel, M. "Highly active meso-microporous $\mathrm{TaON}$ photocatalyst driven by visible light". Chem. Commun. 0. 268-270. 2005.
[12] Hitoki, G., Ishikawa, A., Takata, T., Kondo, J.N., Hara, M. and Domen, K. "Ta3N5 as a novel visible light driven photocatalyst". Chem. Lett. 31. 736-737. 2002.

[13] Ho, C.-T., Low, K.-B., Klie, R.F., Maeda, K., Domen, K., Meyer, R.J. and Snee, P.T. "Formation of sol-gel derived $\mathrm{TaO}_{\mathrm{x}} \mathrm{N}_{\mathrm{y}}$ photocatalysts". J. Phys. Chem. C 115. 647-652. 2011.

[14] Ho, C.-T., Low, K.-B., Jash, P., Shen, H., Snee, P.T. and Meyer, R.J. "Synthesis and characterization of semiconductor tantalum nitride nanoparticles". Chem. Mater. 23. 4721-4725. 2011.

[15] Burda, C., Lou, Y.B., Chen, X.B., Samia, A.C.S., Stout, J. and Gole, J.L. "Enhanced nitrogen doping in $\mathrm{TiO}_{2}$ nanoparticles". Nano Lett 3. 1049-1051. 2003.

[16] Huang, J., Cui, Y. and Wang, X. "Visible light-sensitive ZnGe oxynitride catalysts for the decomposition of organic pollutants in water". Environ. Sci. Technol. 44. 3500-3504. 2010.

[17] Gole, J.L., Stout, J.D., Burda, C., Lou, Y.B. and Chen, X.B. "Highly efficient formation of visible light tunable $\mathrm{TiO}_{2-\mathrm{x}} \mathrm{N}_{\mathrm{x}}$ photocatalysts and their transformation at the nanoscale". J. Phys. Chem. B 108. 1230-1240. 2004.

[18] Yoshida, M., Hirai, T., Maeda, K., Saito, N., Kubota, J., Kobayashi, H., Inoue, Y. and Domen, K. "Photoluminescence spectroscopic and computational investigation of the origin of the visible light response of $(\mathrm{Ga} 1-\mathrm{xZnx})(\mathrm{N} 1-\mathrm{xOx})$ photocatalyst for overall water splitting". J. Phys. Chem. C 114. 15510-15515. 2010.

[19] Maeda, K., Teramura, K., Takata, T., Hara, M., Saito, N., Toda, K. Inoue, Y., Kobayashi, H. and Domen, K. "Overall water splitting on $\left(\mathrm{Ga}_{1-\mathrm{x}} \mathrm{Zn}_{\mathrm{x}}\right)\left(\mathrm{N}_{1-\mathrm{x}} \mathrm{O}_{\mathrm{x}}\right)$ solid solution photocatalyst: Relationship between physical properties and photocatalytic activity". J. Phys. Chem. B 109. 20504-20510. 2005.

[20] Lu, D., Takata, T., Saito, N., Inoue, Y. and Domen, K. "Photocatalyst releasing hydrogen from water". Nature 440. 295295. 2006.

[21] Maeda, K., Teramura, K., Lu, D., Takata, T., Saito, N., Inoue, Y. and Domen, K. "Characterization of $\mathrm{Rh}-\mathrm{Cr}$ mixed-oxide nanoparticles dispersed on $\left(\mathrm{Ga}_{1-\mathrm{x}} \mathrm{Zn}_{\mathrm{x}}\right)\left(\mathrm{N}_{1-\mathrm{x}} \mathrm{O}_{\mathrm{x}}\right)$ as a cocatalyst for visible-light-driven overall water splitting". J. Phys. Chem. B 110. 13753-13758. 2006.

[22] Ikeda, S., Fubuki, M., Takahara, Y.K. and Matsumura, M. "Photocatalytic activity of hydrothermally synthesized tantalate pyrochlores for overall water splitting". Appl. Catal. 300. 186-190. 2006.

[23] Sato, J., Saito, N., Nishiyma, H. and Inoue, Y. "New photocatalyst group for water decomposition of $\mathrm{RuO}_{2}$-loaded p-block Metal (In, $\mathrm{Sn}$, and $\mathrm{Sb}$ ) oxides with $\mathrm{d}^{10}$ configuration". J. Phys. Chem. B 105. 6061-6063. 2001.

[24] Ai, Z., Yang, P. and Lu, X. "Degradation of 4-chlorophenol by a microwave assisted photocatalysis method". J. Hazard. Mater. B 124. 147-152. 2005

[25] Huang, J.H., Wang, X.C., Hou, Y.D., Chen, X.F., Wu, L. and Fu, X.Z. "Degradation of benzene over a zinc germanate photocatalyst under ambient conditions". Environ. Sci. Technol. 42. 7387-7391. 2008.

[26] Huang, J.H., Ding, K.N., Hou, Y.D., Wang, X.C. and Fu, X.Z. "Nanostructuring cadmium germanate catalysts for photocatalytic oxidation of benzene at ambient conditions". Langmuir 25. 83138319. 2009

[27] Tariq, M.A., Faisal, M., Muneer, M. and Bahnemann, D. "Photochemical reactions of a few selected pesticide derivatives and other priority organic pollutants in aqueous suspensions of titanium dioxide". J. Mol. Catal. A: Chem. 265. 231-236. 2007.

[28] Wu, W., Lin, R., Shen, L., Liang, R., Yuan, R. and Wu, L. "Visible-light-induced photocatalytic hydrogenation of 4-nitroaniline over In2S3 photocatalyst in water". Catal. Commun. 40. 1-4. 2013.

[29] Bourett-Courchesne, E.D., Derenzo, S.E. and Weber, M.J. "Development of ZnO:Ga as an ultra-fast scintillator". J. Nucl. Instr. Meth. A 601. 358-363. 2009.

[30] Kim, Y., Atherton, S., Brigham, E.S. and Mallouk, T.E. "Sensitized layered metal oxide semiconductor particles for photochemical hydrogen evolution from nonsacrificial electron donors". J. Phys. Chem. A 97. 11802-11810. 1993.

[31] Kang, X. and Chen, S. "Photocatalytic reduction of methylene blue by $\mathrm{TiO}_{2}$ nanotube arrays: Effects of $\mathrm{TiO}_{2}$ crystalline phase". $J$. Mater. Sci. 45. 2696-2702. 2010. 